\title{
Clinton and Congress weigh in on biomass
}

In an August 12 Executive Order, US President Clinton mandated the establishment of two new committees to help coordinate research on biomass-derived products, including new work in industrial biotechnology and biofuels. The order dovetails with White House requests for increased research funding in these areas, and parallels legislation recently introduced in Congress. Industrial biotechnology experts are applauding the efforts, which should improve interagency cooperation and may increase funding for the studies needed to make biomass economically competitive with petroleum products, but some observers caution that serious political, technical, and economic obstacles remain.

Biomass-derived chemicals and biofuels, often fermented or extracted from corn or soybeans, are typically limited to small-niche markets, a situation many experts contend will continue unless breakthroughs in fundamental research can make them competitive with cheap petroleum products (Nature Biotechnology 16:1022, 1998). But the difficulty of justifying highly speculative research in a corporate environment has left basic biomass research to government and academic scientists, who are often limited by small research budgets and the absence of a coherent national agenda for biomass studies.

With the order, Clinton created the Interagency Council on Biobased Products and Bioenergy, which will be cochaired by the secretary of agriculture and the secretary of energy and include representatives from the Departments of Commerce and the Interior, and the Environmental Protection Agency (EPA; Washington, DC). The council, which is expected to have its first organizational meeting this month, is charged with establishing and overseeing a coherent program for biomass-derived chemical and fuel development. Agencies represented on the council will continue to fund research on biomass through their departmental grant programs, but the council will work to coordinate what were previously disjointed efforts.

David Anton, a researcher at DuPont Central R\&D (Wilmington, DE), explains that in the past, "[The Department of Energy] has always had to have an energy mandate to do what they do and [the Department of Agriculture] has always had an agriculture mandate, and the space between them sometimes left gaps in this area." DuPont is working on several projects to improve biomass-derived plastics, but Anton and others are hopeful that the council will ensure funding for more basic bio- mass research that overlaps the interests of multiple agencies.

In addition to the council, the president established an Advisory Committee on Biobased Products and Bioenergy, whose members will be selected over the next few months from industry, academia, and other nongovernment backgrounds to provide independent assessments of federal bio-

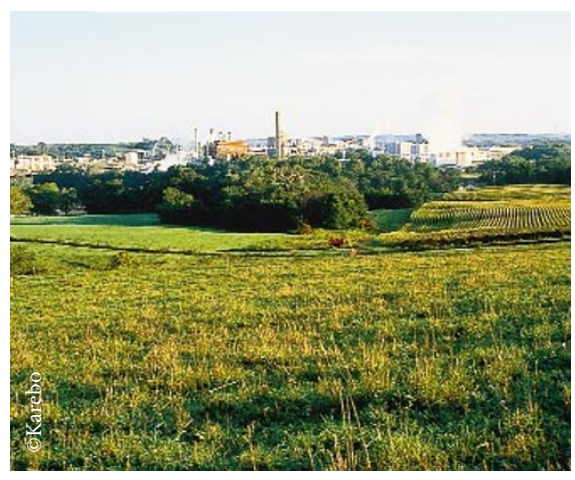

The executive order could generate $\$ 20$ billion in new income for the rural communities where biomass products are manufactured.

mass research. The committee is expected to have its first meeting sometime early in 2000. A new National Biobased Products and Bioenergy Coordination Office, to be set up by the end of this year, will handle research support functions for the council and the committee.

In a memorandum explaining the motives behind the order, the president identified a major goal of the new efforts: tripling US use of biomass-based products and bioenergy by 2010. According to White House projections, this could generate $\$ 20$ billion in new income for the rural communities where biomass products are manufactured, and reduce annual US carbon emissions by 100 million metric tons. In addition to its salutary effect on rural communities, a tripling of production would be a substantial boon to the industrial biotechnology companies producing biomass products.

Such projections are politically popular, but Bob Parmelee, president of biosciences at Cargill (Minneapolis, MN), cautions that the top priority for industry is "price performance, and then way back in the importance line is biodegradability." Cargill already operates a "biorefinery" that produces industrial-grade ethanol from corn, but Parmelee explains that more basic research is needed to make fuel ethanol competitive with petroleum products: "in order to get the economics right, you have to understand how to take unconventional biomass sources and convert them to conventional products," instead of relying on relatively expensive corn feedstocks. Experts have suggested that with additional research on new fermentation technologies, "agricultural waste" such as stalks and leaves could be used as an industrial biomass source.

Others are less optimistic about the prospects for a large-scale switch to biomass. Aside from the potential environmental impact of high-intensity farming, there are also economic barriers to making major changes in agricultural practice. "Whatever you do with the stalks has to have an infrastructure of its procurement and storage and availability that I don't think will ever be built," says Rathin Datta, a researcher at Argonne National Laboratory (Argonne, IL) who has developed separation technologies for plant-derived solvents. Although he doubts that biomass products-particularly biofuels - will live up to their current political hype, Datta is pleased with the prospect of a more coordinated federal research effort. Even without developing new feedstocks, industrial biotechnology processes could be optimized further to produce more economically competitive and environmentally benign fuel additives, plastics, and solvents.

The White House states that its total FY2000 funding request for biomass-related research is $\$ 242$ million, but this figure represents multiple budget categories for such departments as Energy and Agriculture and the EPA, making it difficult to determine how much new funding the president has requested for biomass. In addition, the budget still has to be approved by Congress sometime in 2000. Dick Bradshaw, a senior Department of Energy official, explains that "we don't know what the final shape of our budget is going to be," but says the current request would add $\$ 40$ million in new money to his department's budget alone for biomass projects, and that the Department of Agriculture has also requested an increase in funding for biomass research.

Although budget issues are notoriously contentious in Washington, there is evidence that Congress favors biomass research. A bill introduced in the Senate by Richard Lugar (RIN) in April closely parallels the goals of the Executive Order, and a similar measure has also been introduced in the House. Both bills will be discussed in committee meetings when Congress reconvenes later this year, and observers expect that the bills will receive bipartisan support when they are brought before the full House and Senate for approval. Alan Dove 